\title{
Treatment of $A C$ dislocation by reconstructing $C C$ and $A C$ ligaments with allogenic tendons compared with hook plates
}

\author{
Guheng Wang ${ }^{1}$, Renguo Xie ${ }^{1,2^{*}}$ (D), Tian Mao ${ }^{1}$ and Shuguo Xing ${ }^{1}$
}

\begin{abstract}
Background: The purpose of this study was to compare outcomes between allograft reconstruction and hook plate fixation for acute dislocation of the acromioclavicular joint with a minimum 2-year follow-up.

Methods: A retrospective comparative study of patients treated for acute acromioclavicular joint dislocation from February 2010 to December 2014 in our hospital, consisting of 16 patients who were followed-up, was performed. Eight patients were treated for acute AC dislocation and underwent surgical reconstruction as follows: the coracoclavicular and acromioclavicular ligaments were reconstructed with the allogenic tendon. The other eight patients were treated with hook plates to maintain the AC joint reset. At the latest follow-up, radiographic analysis and the Constant and University of California-Los Angeles (UCLA) scores were used to evaluate shoulder function. The satisfaction of the patients in terms of the efficacy and visual analog scale (VAS) data were also recorded.

Results: After an average follow-up of 30.3 months (range 24-46 months), no patient had dislocated their joint again at the final follow-up based on X-ray examination. The Constant score was 94.4 for the allogenic tendon group and 93.8 for the hook plate group ( $P=0.57)$. According to the UCLA scale $(P=0.23)$ or VAS $(P=0.16)$, we found no significant difference between the two groups. All patients reported that they were very satisfied or satisfied with the outcome of surgery, and no significant difference $(P=0.08)$ was found between the two groups.

Conclusions: The use of allogenic tendon for reconstruction of the coracoclavicular and acromioclavicular ligaments shows excellent outcomes in terms of the recovery of clinical function or radiographic outcomes for acute AC dislocation. Compared with the hook plate, the hardware did not need to be removed.
\end{abstract}

Keywords: Surgery, Acromioclavicular joint dislocation, Coracoclavicular ligaments, Acromioclavicular ligaments, Allogenic tendon, Hook plate

\section{Background}

Acromioclavicular (AC) joint dislocation is a common injury, which accounts for approximately $9 \%$ of shoulder injuries [1]. When AC joint dislocation occurs, it not only produces shoulder pain and abnormal activity symptoms but also greatly affects the strength, flexibility, and movement of the entire upper

\footnotetext{
* Correspondence: xrg1969@yahoo.com

${ }^{1}$ Department of Hand Surgery, Affiliated Hospital of Nantong University, 20\# West Temple Road, Nantong 226001, People's Republic of China

${ }^{2}$ Department of Hand Surgery, Shanghai General Hospital, 650\# Songjiang Road, Shanghai 201620, People's Republic of China
}

extremity. Because previous techniques are associated with frequent complications, such as loss of reduction, fracture of the coracoids, and loosening [2-6], many studies have evaluated potential improvements in the surgical management of $\mathrm{AC}$ joint dislocation. Many methods exist, indicating that an ideal method still needs to be explored. Considering the possibility of vertical and anteroposterior displacement of the clavicle in AC joint dislocation, we adopted a method to reduce and maintain the reduction of the $\mathrm{AC}$ joint using an allogenic tendon to reconstruct the coracoclavicular and acromioclavicular ligaments in acute

(c) The Author(s). 2018 Open Access This article is distributed under the terms of the Creative Commons Attribution 4.0 International License (http://creativecommons.org/licenses/by/4.0/), which permits unrestricted use, distribution, and 
injuries. We also compared it with the clavicular hook plate treatment to assess the merits and demerits of this method.

\section{Methods}

\section{Patients}

A retrospective study of patients with acute $\mathrm{AC}$ joint dislocation who were treated in our hospital between February 2010 and December 2014 was performed. The institutional ethics committee approved the study, and informed consent was obtained from all study participants. In this study, eight patients (six male, two female) with an average age of 49.0 years were treated with an allogenic tendon to reconstruct the coracoclavicular and acromioclavicular ligaments after AC joint dislocation. At the same time, eight atients (five male, three female) with an average age of 41.3 years were treated with the hook plate for fixation of AC joint dislocation. Patients with chronic dislocation ( $\geq 3$ weeks after trauma) and patients who received any operative treatment of the injured shoulder were excluded. Patients with accompanying coracoid fracture, shoulder wounds, and chronic infections were also excluded from this study.

According to the Rockwood classification, there were six cases of type III, two of type IV, and eight of type V. The mean time from injury to surgery was 2.9 (range 15) days. Of all injuries, 14 were caused by traffic accidents, 1 by a simple fall, and 1 by blunt trauma (Table 1).

\section{Surgical technique}

\section{Allogenic tendon}

Under interscalene regional block or general anesthesia, the patient was placed in the beach-chair position and the upper limb draped free. A saber cut incision (Fig. 1) was made in line from the coracoid process to the medial AC joint. After development of subcutaneous flaps, the deltotrapezial fascia was taken down subperiosteally, exposing the clavicle, AC joint, and coracoid process [7].

After the AC joint was exposed, the coracoclavicular (CC) and AC ligaments were identified to ensure that they were ruptured. With the deltoid flap retracted, the base of the coracoid process was exposed, and a soft tissue tunnel was made. After the AC joint was reduced, the reduction was maintained with direct pressure with assistance. Corresponding to the trapezoid ligament and conoid ligament attachment in the clavicle, two tunnels, using a 4.0 and a $3.5 \mathrm{~mm}$ drill bit, were drilled separately at a distance of approximately 20 and $40 \mathrm{~mm}$ from the distal end of the clavicle (Fig. 2a, b). Another drill tunnel $(3.5 \mathrm{~mm})$ was positioned on the acromion approximately $15 \mathrm{~mm}$ from the AC joint (Fig. 2c). This corresponds to the acromioclavicular ligament. At this time, the allogenic tendon (Tissuebank of the Orthopedic Institute of the People's Liberation Army in Beijing) was taken out of the sealed bag, washed with saline, and placed in saline with antibiotics for $30 \mathrm{~min}$ before use. The flexor digitorum profundus tendon was usually selected because its length and width meet the requirements.

Table 1 Data of the 16 evaluated patients

\begin{tabular}{|c|c|c|c|c|c|}
\hline Patient & Age/sex side & Mechanism of injury & Plate removal (months) & Follow-up (months) & $\overline{\text { Type of separation }}{ }^{a}$ \\
\hline \multicolumn{6}{|c|}{ Allogenic tendon } \\
\hline 1 & $34 /$ male right & Fall from height & - & 28 & IV \\
\hline 2 & $43 /$ male left & Traffic accident & - & 43 & V \\
\hline 3 & 59/male left & Traffic accident & - & 24 & V \\
\hline 4 & 64/female right & Traffic accident & - & 29 & IV \\
\hline 5 & 72/male left & Traffic accident & - & 29 & III \\
\hline 6 & 23/male left & Traffic accident & - & 33 & III \\
\hline 7 & 34/female right & Traffic accident & - & 27 & V \\
\hline 8 & $63 /$ male left & Traffic accident & - & 25 & V \\
\hline \multicolumn{6}{|c|}{ Hook plate } \\
\hline 1 & $56 /$ male right & Blunt trauma & 10 & 30 & III \\
\hline 2 & 22/male left & Traffic accident & 7 & 31 & III \\
\hline 3 & $34 /$ male left & Traffic accident & 5 & 24 & V \\
\hline 4 & $31 /$ male left & Traffic accident & 8 & 26 & V \\
\hline 5 & $42 /$ female right & Traffic accident & 11 & 46 & III \\
\hline 6 & 37/female right & Traffic accident & 8 & 39 & III \\
\hline 7 & $63 /$ male right & Traffic accident & 11 & 25 & V \\
\hline 8 & 45/female left & Traffic accident & 12 & 26 & V \\
\hline
\end{tabular}

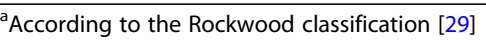




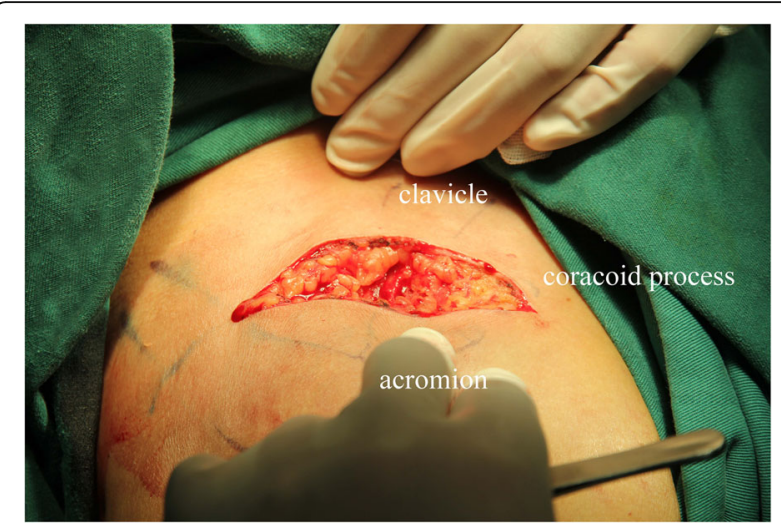

Fig. 1 Saber cut incision spanning the AC joint to just proximal to the coracoid process

(The time from tendon harvest to use was approximately 1-2 months.) Tendon donors were usually healthy and died between 20 and 50 years old. Their deaths were often caused by accidents. If one tendon was not long enough, we used two allogenic tendons to reconstruct the coracoclavicular ligament and the acromioclavicular ligament separately. Attention was paid to ensure that the graft looked firm and appeared fresh.

The prepared allogenic tendon was then pushed through the A tunnel with a curved hemostat. Next, the allogenic tendon was passed around the coracoid process and then, with the help of a passing wire, passed through the B tunnel, which was previously made. Then, the allogenic tendon was continually passed through the

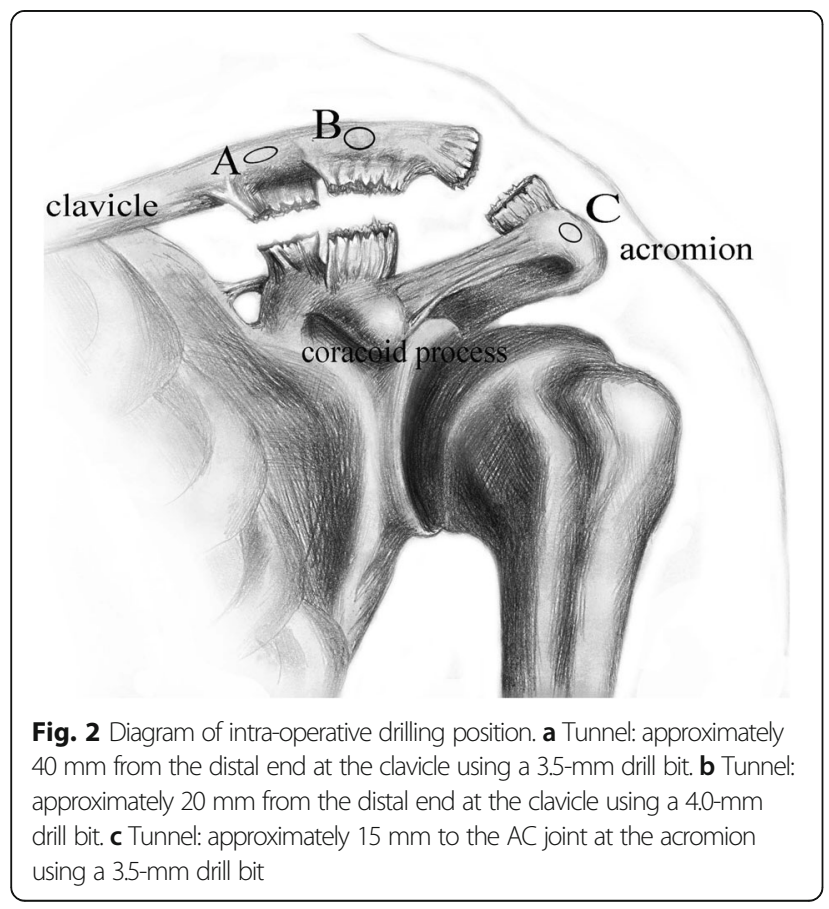

$\mathrm{C}$ tunnel at the acromion on the clavicle. Finally, the allogenic tendon was pushed through the $\mathrm{B}$ tunnel again below the clavicle to reach the surface of the clavicle. Subsequently, the two free ends of the allogenic tendon were secured to each other on the surface of the clavicle with maximum manual tension between the $\mathrm{A}$ and B tunnels using 3-0 nonabsorbable surgical suture (Ethibond Johnson \& Johnson, New Brunswick, US) (Fig. 3). Throughout the process, assistance helped to maintain the reduction of the $\mathrm{AC}$ joint, and both the trapezoid and conoid ligaments as well as the acromioclavicular ligament were reconstructed. Next, the trapezius-deltoid fascia was repaired and the wound closed. Before and after surgery, X-rays of the AC joint were obtained, and the dislocation is shown in Fig. 4. The X-ray after surgery confirmed that the AC joint was restored.

\section{Hook plate}

The surgical position and anesthesia were performed as in the allogenic tendon group. Centered on the AC joint, a 5- to 7-cm skin incision was made to expose the dislocation and ensure that the coracoclavicular and acromioclavicular ligaments were ruptured. The articular disc was removed if injured. The hook plate was then used to fix the dislocation (3.5 mm LCP clavicular hook plate, Synthes GmbH, Solothurn, Switzerland) as the end of the hook was inserted under the acromion. Before application of the hook plate, the depth of the acromion was measured, and the plate was pre-bent to perfectly fit the clavicle. When the hook plate was placed, $3.5-\mathrm{mm}$ screws were used to fix it in place. The coracoclavicular and acromioclavicular ligaments were then repaired with \#5 nonabsorbable surgical suture (Ethibond Johnson \& Johnson, New Brunswick, US).

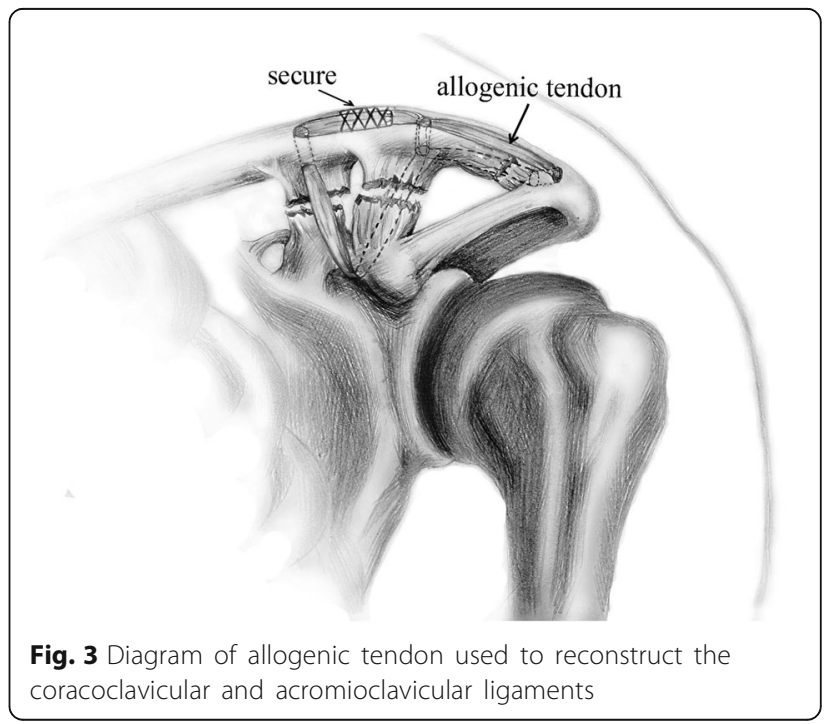




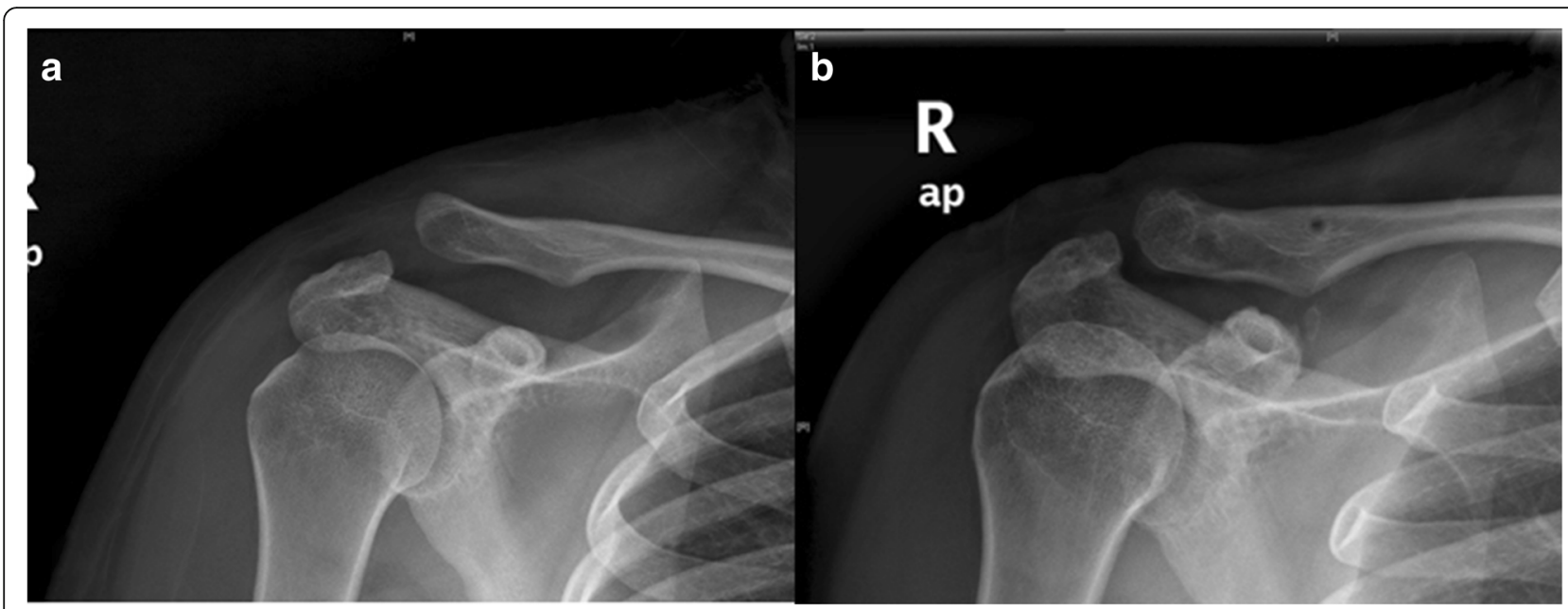

Fig. 4 a X-rays of AC joint dislocation before surgery. $\mathbf{b}$ X-rays of AC joint dislocation after surgery reconstructing the coracoclavicular and acromioclavicular ligaments with the allogenic tendon

Finally, the deltoid trapezoid fascia was closed with resorbable sutures, and the wound was closed in layers. The hook plate was removed at 9.0 (range 5-12) months after the surgery.

\section{Postoperative management}

A sandbag was used to compress the wound for $24 \mathrm{~h}$ after surgery. Postoperatively, the patient was placed in a shoulder immobilizer for 4 weeks, although movement of the wrist and elbow was encouraged immediately after surgery. After 4 weeks, shoulder joint motion, including the pendulum exercise, began; however, heavy physical work was not permitted until 3 months. Patients were not allowed to participate in sports activities until 6 months after the operation.

\section{Clinical evaluation}

All patients were asked to report whether they have any particular discomfort in the shoulder, which may be related to the overall surgery satisfaction (very satisfied, satisfied, partially satisfied, or not satisfied).

During follow-up, the appearance of the shoulder was assessed to determine whether there were any deformities, such as projections of the distal clavicle. At the same time, we also took X-rays and evaluated the radiographic findings, including the occurrence of osteoarthritic changes and the complete reduction degree of the AC joint. A visual analog scale (VAS: range 0-10; 0 represents no pain and 10 represents maximal imaginable pain) was used to evaluate the pain postoperatively.

Clinical evaluation of patients was performed using both the Constant [8] and University of California-Los Angeles (UCLA) [9] scoring systems. The Constant score is graded from 0 to 100 , where 100 is best possible score, and consists of four dimensions: pain (0-15 points), activity level (0-20 points), range of movement (0-40 points), and power ( $0-25$ points). We assumed that scores $\geq 90,80-89,70-79$ and $<70$ indicated excellent, good, fair, and poor, respectively. The UCLA score consisted of pain ( $0-10$ points), function ( $0-10$ points), range of motion ( $0-5$ points), strength $(0-5$ points), and the patient's satisfaction ( $0-5$ points). The total UCLA score is 35 points, and 34 or $35,29-33$, and $\leq 29$ indicated excellent, good, and poor, respectively.

\section{Statistical methods}

The $t$ test was used to evaluate significant differences between the two study groups for continuous variables, and the Wilcoxon test was used to evaluate significant differences for patient satisfaction during follow-up. A value of $P$ less than 0.05 was considered as statistically significant. Statistical analysis was performed with SPSS version 16.0 software (SPSS, Chicago IL, USA).

\section{Results}

In the allogenic tendon group, the operative procedure was performed by the corresponding author, whereas all patients in the hook plate group were operated on by seniors. No patient reported any immune problems related to the allogenic tendon or hook plate.

In the allogenic tendon group, the eight patients were followed up, and the total follow-up ranged from 25 to 43 months, with a mean of 29.8 months. In the hook plate group, the total follow-up ranged from 24 to 46 months, with a mean of 30.9 months. No patients lost reduction on the final follow-up based on the X-ray results, and no patients had shoulder deformities.

All patients reported that they were very satisfied or satisfied with the outcome of the surgery. Three patients were satisfied, and five were very satisfied in the 
allogenic tendon group, whereas two patients were satisfied and six were very satisfied in the hook plate group. Although, there were more "very satisfied" results in the hook plate group, this difference was not significant $(P=0.08)$.

All patients returned to work without pain, and the VAS scale showed no significant difference between the two groups $(P=0.16)$.

\section{Function}

No significant differences were found between the two groups with regard to the Constant score $(P=0.57)$, with 94.4 in the allogenic tendon group (86-100, number in brackets indicates the range of the variables) compared to 93.8 in the hook plate group (84-98) (Table 2). The results for all patients were rated as excellent or good according to the score. Detailed results of the functional questionnaire are shown in Table 2.

No significant differences were found between the two groups with regard to the UCLA score, with $33.5(30-35)$ for the allogenic tendon group and 34.1 (31-35) for the hook plate group $(P=0.23)$.

\section{Discussion}

The aim of our study was to introduce and evaluate the method using allogenic tendon to reconstruct the $\mathrm{CC}$ and $\mathrm{AC}$ ligaments for acute $\mathrm{AC}$ joint dislocation, and we also compared it with the hook plate to determine its merits and disadvantages. We believe that Rockwood types IV and $\mathrm{V}$ of $\mathrm{AC}$ joint injuries require operative treatment, and we proposed surgical treatment for patients with type III lesions involved in heavy labor or patients who participate in sports activities.

The tendon allograft played an important role in tendon and ligament reconstruction, particularly for the patients who have a shortage of autograft tendons or who do not want to use their own normally functioning tendons. Allograft tissue has many advantages over autograft tissue, including unlimited size, lack of donor site morbidity, and availability for revision surgery. The drawbacks of allogeneic tendons are that they may cause minimal immunogenicity and increase the chance of rejection compared with autograft tissues. The tendon as an allograft has low cellularity and is preserved at $-80^{\circ}$ to elicit minimal immunogenicity. In our study, we did not find any adverse reactions after grafting of allogenic tendons, and the preliminary clinical assessment did not find any significant adverse reactions [10-12]. Currently, the risk of viral transmission through allograft tissue transplantation is extremely low due to proper donor screening and tissue processing. The tendons we used were fully tested to exclude infectious diseases and sterilized to prevent the risk of infection from grafts. This documentation allowed us to use tendons from this company for recipients in our country. Therefore, we consider that reconstructing the $\mathrm{CC}$ and $\mathrm{AC}$ ligaments with allogenic tendons is a safe approach.

Up to now, more than 70 types of methods have been described for the treatment of acute AC joint dislocation, but no one method has been considered the best [13-32]. These surgical techniques can be grouped broadly into types such as fixation of the AC joint or fixation between the coracoid and clavicle and as dynamic muscle transfer or ligament reconstruction. The current literature shows the conoid ligament guarding against anterosuperior loading and the trapezoid guarding against posterior loading of the clavicle [33]. Debski et al. also clarified that the $\mathrm{AC}$ ligaments play an important role in constraint of horizontal motion of the distal clavicle [34]. Predicting that reconstructing the CC and AC ligaments with allogenic tendon would provide good stability of the AC joint, we designed and used this method and compared it with the hook plate procedure.

In the anatomic reconstruction method, two clavicle tunnels were used, and the allogenic tendon was passed around the base of the coracoid process (V shape), which recreated the anatomy of both the conoid and trapezoid ligaments. Based on the advantages of the $\mathrm{V}$-shape technique, it was more likely that the patient would achieve greater overall stability by reducing the amount of abnormal translation. To successfully reconstruct the conoid and trapezoid ligaments using this technique, adequate exposure to the base of the coracoid is helpful and should be obtained. Subcoracoid suture placement is not completely anatomical, and poor visualization risks injury to nearby neurovascular structures; therefore, the separation and drilling should be performed with extreme care to maintain coracoid integrity and avoid potential fractures. The method we used was similar to that of Saccomanno [35] and was used at nearly the same time. The difference is that we used allogenic tendons and omitted the process of harvesting tendons.

Table 2 Clinical functional outcome of treated shoulder

\begin{tabular}{llllll}
\hline & Pain (15) & Activity level (20) & Range of movement (40) & Power (25) & Constant score (100) \\
\hline Allogenic tendon & 14.3 & 19.5 & 37.3 & 23.4 & 94.4 \\
Hook plate & 14.4 & 19.4 & 37.8 & 22.3 & 93.8 \\
$P$ value & $>0.05$ & $>0.05$ & $>0.05$ & $>0.05$ & $>0.05$ \\
\hline
\end{tabular}


There are several causes of chronic pain after the surgical treatment of AC dislocations, one of which is persistent anteroposterior instability of the clavicle [36, 37]. By adding AC ligament reconstruction, the horizontal stability of the clavicle will be further strengthened. In our study, the VAS was 0.38 , indicating that the results are quite good. Biomechanical studies of $\mathrm{AC}$ joint reconstruction with free-tissue graft for both the $\mathrm{CC}$ and $\mathrm{AC}$ ligaments provide $\mathrm{AC}$ joint stability similar to that of the intact $\mathrm{AC}$ joint and significantly better than that of the modified Weaver-Dunn procedure [38, 39]. Carofino and Mazzocca [40] used a technique that involves reconstruction of the superior AC ligament and capsule. In the presented method, we recreate the superior and inferior AC ligament and attain better stability. The results are encouraging and satisfactory.

Because of the good clinical outcomes, the hook plate remains one of the most commonly used methods for acute AC dislocations [41-44]. According to follow-up, the results confirmed that the efficacy of the clavicular hook plate was high. The advantage of the hook plate was the relatively easy implantation procedure and that it can provide immediate stability, which allows rapid healing of the torn ligaments and ensures early rehabilitation with a minimal risk of loss of reduction or implant failure. However, the implant had to be removed, which was a disadvantage and increased the rate of separation and medical costs. Compared with the hook plate, the method of allogenic tendon reconstruction did not require a second surgery and reduced the patient's pain.

We did not find any infections or other complications in either series. The hook plate is a reliable fixation tool for complete AC joint dislocations, ensuring immediate stability and allowing early mobilization with good functional and cosmetic results. With allogenic tendon grafts, the damaged anatomy can be restored without sacrificing any tendons or ligaments. Based on several in vitro biomechanical studies [38, 45-48] and our research, allogenic tendon graft reconstructions are likely to provide available alternatives for the treatment of operable AC joint dislocations. By controlling both the vertical and anteroposterior displacements of the clavicle, this technique offers strong biological reconstruction to maintain the AC joint reduction. Limitations of our study include the small number of patients and only acute injuries being studied. Further studies are necessary to confirm the reliability of this new method.

\section{Conclusions}

We prefer allografts because there is no donor site morbidity involved, and they are of adequate length to loop around the coracoid and over the clavicle. Moreover, they are readily available at our institution. Both techniques, allogenic tendon reconstruction and hook plate fixation, are effective procedures for the surgical treatment of AC joint acute dislocations of Rockwood III, IV, and V. There is no principle difference in functional outcomes between the two treatments; however, patients with allogenic tendon reconstruction do not require hardware removal and have less pain.

\section{Abbreviations}

AC: Acromioclavicular; CC: Coracoclavicular; UCLA: University of California-Los Angeles; VAS: Visual analog scale

\section{Acknowledgements \\ We thank Rongrong Zhang for her help with drawing the diagram.}

\section{Availability of data and materials}

All data generated or analyzed during this study are included in this published article.

\section{Authors' contributions}

GHW had substantial contributions to collecting and analysis the data, assisted with operation, and was a major contributor in writing the manuscript. RGX had substantial contributions to conception and design of the study, organized the operation, and revised the manuscript. TM assisted with the operation and collected data in the study. SGX assisted with the operation and collected data in the study. All authors read and approved the final manuscript.

\section{Ethics approval and consent to participate}

This study was approved by ethical committee of Affiliated Hospital of Nantong University and in accordance with the Declaration of Helsinki.

\section{Consent for publication}

All consents to publish from the patients who took part in this study were obtained.

\section{Competing interests}

The authors declare that they have no competing interests.

\section{Publisher's Note}

Springer Nature remains neutral with regard to jurisdictional claims in published maps and institutional affiliations.

Received: 2 June 2017 Accepted: 3 July 2018

Published online: 11 July 2018

References

1. Shaw MB, Mclnerney JJ, Dias JJ, Evans PA. Acromioclavicular joint sprains: the post-injury recovery interval. Injury. 2003;34:438-42. https://doi.org/10. 1016/S0020-1383(02)00187-0.

2. Millett PJ, Braun S, Gobezie R, Pacheco $\Vdash H$. Acromioclavicular joint reconstruction with coracoacromial ligament transfer using the docking technique. BMC Musculoskelet Disord. 2009;14:10-6. https://doi.org/10. 1186/1471-2474-10-6.

3. Boileau P, Old J, Gastaud O, Brassart N, Roussanne Y. All-arthroscopic Weaver-Dunn-Chuinard procedure with double-button fixation for chronic acromioclavicular joint dislocation. Arthroscopy. 2010;26:149-60. https://doi. org/10.1016/j.arthro.2009.08.008. Epub 2009 Dec 30.

4. Spencer EE Jr. Treatment of grade III acromioclavicular joint injuries: a systematic review. Clin Orthop Relat Res. 2007;455:38-44.

5. Tienen TG, Oyen JF, Eggen P. A modified technique of reconstruction for complete acromioclavicular dislocation: a prospective study. Am J Sports Med. 2003;31:655-9.

6. Weinstein DM, McCann PD, Mcllveen SJ, Flatow EL, Bigliani LU. Surgical treatment of complete acromioclavicular dislocations. Am J Sports Med. 1995:23:324-31.

7. Nicholas SJ, Lee SJ, Mullaney MJ, Tyler TF, McHugh MP. Clinical outcomes of coracoclavicular ligament reconstructions using tendon grafts. Am J Sports Med. 2007;35:1912-7. https://doi.org/10.1177/0363546507304715. 
8. Constant CR, Murley AH. A clinical method of functional assessment of the shoulder. Clin Orthop Relat Res. 1987;214:160-4.

9. Ellman H, Hanker G, Bayer M. Repair of the rotator cuff. End-result study of factors influencing reconstruction. J Bone Joint Surg Am. 1986;68:1136-44.

10. Krocker D, Matziolis G, Pruss A, Perka C. Reconstruction of the extensor mechanism using a free, allogenic, freeze-dried patellar graft. Unfallchirurg. 2007;110:563-6.

11. Xie RG, Tang JB. Allograft tendon for second-stage tendon reconstruction. Hand Clin. 2012;28:503-9. https://doi.org/10.1016/j.hcl.2012.08.011.

12. Zhang Y, Yang K, Zhu W. Experimental research and clinical application of allogenic tendon grafting. Zhonghua Wai Ke Za Zhi. 1995;33:539-41.

13. Bannister GC, Wallace WA, Stableforth PG, Hutson MA. The management of acute acromioclavicular dislocation. A randomized prospective controlled trial. J Bone Joint Surg Br. 1989;71:848-50.

14. Boström Windhamre HA, von Heideken JP, Une-Larsson VE, Ekelund AL. Surgical treatment of chronic acromioclavicular dislocations: a comparative study of Weaver-Dunn augmented with PDS-braid or hook plate. J Shoulder Elb Surg. 2010;19:1040-8. https://doi.org/10.1016/j.jse.2010.02.006

15. Bosworth BM. Acromioclavicular separation: new method of repair. Surg Gynecol Obstet. 1941;73:866-71.

16. Brunelli $G$, Brunelli $F$. The treatment of acromio-clavicular dislocation by transfer of the short head of the biceps. Int Orthop. 1988;12:105-8.

17. Dumontier C, Sautet A, Man M, Apoil A. Acromioclavicular dislocations: treatment by coracoacromial ligamentoplasty. J Shoulder Elb Surg. 1995;4: $130-4$.

18. Ejam S, Lind T, Falkenberg B. Surgical treatment of acute and chronic acromioclavicular dislocation Tossy type III and V using the Hook plate. Acta Orthop Belg. 2008;74:441-5.

19. Jiang $C$, Wang $M$, Rong G.Proximally based conjoined tendon transfer for coracoclavicular reconstruction in the treatment of acromioclavicular dislocation. Surgical technique. J Bone Joint Surg Am. 2008;90: Suppl 2 Pt 2: 299-308. https://doi.org/10.2106/JBJS.H.00438.

20. Kappakas GS, McMaster J. Repair of acromioclavicular separation using a Dacron prosthesis graft. Clin Orthop Relat Res. 1978;31:247-51.

21. Korsten K, Gunning AC, Leenen LP. Operative or conservative treatment in patients with Rockwood type III acromioclavicular dislocation: a systematic review and update of current literature. Int Orthop. 2014;38:831-8. https:// doi.org/10.1007/s00264-013-2143-7.

22. Larsen E, Bjerg-Nielsen A, Christensen P. Conservative or surgical treatment of acromioclavicular dislocation. A prospective, controlled, randomized study. J Bone Joint Surg Am. 1986;68:552-5.

23. Lemos MJ. The evaluation and treatment of the injured acromioclavicular joint in athletes. Am J Sports Med. 1998;26:137-44.

24. Luis GE, Yong CK, Singh DA, Sengupta S, Choon DS. Acromioclavicular joint dislocation: a comparative biomechanical study of the palmaris-longus tendon graft reconstruction with other augmentative methods in cadaveric models. J Orthop Surg Res. 2007;27(2):22.

25. Mlasowsky B, Brenner P, Düben W, Heymann H. Repair of complete acromioclavicular dislocation (Tossy stage III) using Balser's hook plate combined with ligament sutures. Injury. 1998;19:27-232.

26. Nüchtern JV, Sellenschloh K, Bishop N, Jauch S, Briem D, Hoffmann M, et al. Biomechanical evaluation of 3 stabilization methods on acromioclavicular joint dislocations. Am J Sports Med. 2013;41:1387-94. https://doi.org/10. 1177/0363546513484892.

27. Paavolainen P, Björkenheim JM, Paukku P, Slätis P. Surgical treatment of acromioclavicular dislocation: a review of 39 patients. Injury. 1983;14:415-20.

28. Press J, Zuckerman JD, Gallagher M, Cuomo F. Treatment of grade II acromioclavicular separations. Operative versus nonoperative management. Bull Hosp Jt Dis. 1997;56:77-83.

29. Rockwood CA Jr, Williams GR Jr, Young DC. Disorders of the acromioclavicular joint. In: Rockwood Jr CA, Matsen FAlll, editors. The shoulder. 2nd ed. Philadelphia: WB Saunders; 1998. p. 483-553.

30. Salem KH, Schmelz A. Treatment of Tossy III acromioclavicular joint injuries using hook plates and ligament suture. J Orthop Trauma. 2009;23:565-9. https://doi.org/10.1097/BOT.0b013e3181971b38.

31. Weaver JK, Dunn HK. Treatment of acromioclavicular injuries, especially complete acromioclavicular separation. J Bone Joint Surg Am. 1972;54: 1187-94.

32. De Carli A, Lanzetti RM, Ciompi A, Lupariello D, Rota P, Ferretti A. Acromioclavicular third degree dislocation: surgical treatment in acute cases. J Orthop Surg Res. 2015;28:10:13. https://doi.org/10.1186/s13018-014-0150-z.
33. Debski RE, Parsons IM 3rd, Fenwick J, Vangura A. Ligament mechanics during three degree-of-freedom motion at the acromioclavicular joint. Ann Biomed Eng. 2000;28:612-8.

34. Debski RE, Parsons IM 4th, Woo SL, Fu FH. Effect of capsular injury on acromioclavicular joint mechanics. J Bone Joint Surg Am. 2001;83:1344-51.

35. Saccomanno MF, Fodale M, Capasso L, Cazzato G, Milano G. Reconstruction of the coracoclavicular and acromioclavicular ligaments with semitendinosus tendon graft: a pilot study. Joints. 2014;2:6-14.

36. Jerosch J, Filler T, Peuker E, Greig M, Siewering U. Which stabilization technique corrects anatomy best in patients with AC-separation? An experimental study. Knee Surg Sports Traumatol Arthrosc. 1999;7:365-72.

37. Taft TN, Wilson FC, Oglesby JW. Dislocation of the acromioclavicular joint. An end-result study. J Bone Joint Surg Am. 1987;69:1045-51.

38. Grutter PW, Petersen SA. Anatomical acromioclavicular ligament reconstruction: a biomechanical comparison of reconstructive techniques of the acromioclavicular joint. Am J Sports Med. 2005;33:1723-8. https://doi. org/10.1177/0363546505275646.

39. Michlitsch MG, Adamson GJ, Pink M, Estess A, Shankwiler JA, Lee TQ. Biomechanical comparison of a modified Weaver-Dunn and a free-tissue graft reconstruction of the acromioclavicular joint complex. Am J Sports Med. 2010;38:1196-203. https://doi.org/10.1177/0363546509361160

40. Carofino BC, Mazzocca AD. The anatomic coracoclavicular ligament reconstruction: surgical technique and indications. J Shoulder Elb Surg. 2010;19:37-46. https://doi.org/10.1016/j.je.2010.01.004.

41. De Baets T, Truijen J, Driesen R, Pittevils T. The treatment of acromioclavicular joint dislocation Tossy grade III with a clavicle hook plate. Acta Orthop Belg. 2004;70:515-9.

42. Folwaczny EK, Yakisan D, Sturmer KM. The Balser plate with ligament suture: a dependable method of stabilizing the acromioclavicular joint. Unfallchirurg. 2000;103:731-40.

43. Henkel T, Oetiker R, Hackenbruch W. Treatment of fresh Tossy III acromioclavicular joint dislocation by ligament suture and temporany fixation with the clavicular hooked plate. Swiss Surg. 1997;3:160-6.

44. Sim E, Schwarz N, Höcker K, Berzlanovich A. Repair of complete acromioclavicular separations using the acromioclavicular-hook plate. Clin Orthop Relat Res. 1995;314:134-42.

45. Costic RS, Labriola JE, Rodosky MW, Debski RE. Biomechanical rationale for development of anatomical reconstructions of coracoclavicular ligaments after complete acromioclavicular joint dislocations. Am J Sports Med. 2004; 32:1929-36. https://doi.org/10.1177/0363546504264637.

46. Harris RI, Wallace AL, Harper GD, Goldberg JA, Sonnabend DH, Walsh WR. Structural properties of the intact and the reconstructed coracoclavicular ligament complex. Am J Sports Med. 2000;28:103-8.

47. Jari R, Costic RS, Rodosky MW, Debski RE. Biomechanical function of surgical procedures for acromioclavicular joint dislocations. Arthroscopy. 2004;20: 237-45. https://doi.org/10.1016/j.arthro.2004.01.011.

48. Lee SJ, Nicholas SJ, Akizuki KH, McHugh MP, Kremenic IJ, Ben-Avi S. Reconstruction of the coracoclavicular ligaments with tendon grafts: a comparative biomechanical study. Am J Sports Med. 2003;31:648-55.

Ready to submit your research? Choose BMC and benefit from

- fast, convenient online submission

- thorough peer review by experienced researchers in your field

- rapid publication on acceptance

- support for research data, including large and complex data types

- gold Open Access which fosters wider collaboration and increased citations

- maximum visibility for your research: over $100 \mathrm{M}$ website views per year

At BMC, research is always in progress.

Learn more biomedcentral.com/submissions 